\title{
An Examination on Advanced MPPT Methods For PV Systems Under Normal \& Partial Shading Conditions
}

\author{
Buchibabu P, Jarupula Somlal
}

\begin{abstract}
Maximum power point tracking is an method to derive maximum amount of power from $P V$ array irrespective of its atmospheric and load conditions. There is only singular point on the PV graph where we can obtain the maximum power more popularly known as MPP. Basic conventional methods namely Perturb \& Observe $(P \& O)$, Incremental Conductance method ( $I N C$ ) \& Fractional open circuit voltage have a very elementary design in obtaining the maximum power which are unsuitable to track the maximum power under partial shade conditions \& rapid atmospheric change conditions. Hence to overcome the above situations MPPT methods based on partial shade conditions are illustrated in these Paper. In addition to these the advancement made in conventional methods regarding the step size is also proposed in these paper. Advanced MPPT methods based on Artificial Intelligence which are bio inspired algorithms are presented.
\end{abstract}

Keywords : MPPT,Partial shade, Artificial Intelligence \& Bio-inspired algorithms.

\section{INTRODUCTION}

The era of Electrical Energy from sustainable power source (RES) has grown a ton in ongoing decades, basically because of expanded interest for power, just as the worldwide concentrated endeavour to defeat the unsafe natural impacts brought about by contamination vitality sources, for example, oil, coal, flammable gas, and others. Embedded in this situation, sun based vitality has risen as a promising RES because of its plenitude over the world's surface. Another reason the PV modules have gained importance these recent time is due to incentives given by government [1].

A great amount of research work in a grid system is emphasised on Inverter topology. The main aim of inverters hereis not only the inversion of DC power to AC power but it should also track the maximum power irrespective of adverse conditions which is total based on the advancement of technology used in algorithms [2]. But unfortunately the main drawback here is the efficiency of the solar panels are in the range of $18 \%$ to $20 \%$ but the recent research suggests that a high efficiency of $23 \%$ to $27 \%$ is possible [3][4]. In addition to the above statistics surprisingly a high efficiency around $30 \%$ was made from Ga-As photovoltaics [5].

Revised Manuscript Received on September28, 2019.

* Correspondence Author

BUCHIBABU P, Assistant Professor ,EEE Department, Gnits College, Hyd, Telangana, India

Dr.JARUPULA SOMLAL, Professor in EE Department ,KL university,Guntur,AP,India
The analysis of above data reveals that the conversion efficiency of above of solar panels is very low which enabled all the researchers to emphasis their research works on the extraction of maximum power, so here comes the role of novel MPPT methods used in PV systems. The paper is structured in the such way that Section-1 speaks about the introduction, Section-2 describes basic MPPT techniques, Section-3 emphasis on advancement made in MPPT techniques and section -4 ends with bio inspired MPPT techniques for partial shade conditions.

\section{MPPT TECHNIQUES}

The main criteria for the adoption of MPPT techniques is to give assurance suchthat the maximum power is squeezed from PV panels irrespective of its atmospheric conditions. In a normal sense the MPPT methods reads the values of voltage and current and modify the duty ratio of converter such that they try to squeeze the maximum power from PV panels. Under cloudy environment or shady conditions the PV graph represents many number of Local Maximum Power (LMP) \& Global Maximum Power (GMP). So the basic approach MPPT methods namely P\&O method, Fractional Open Circuit Method,Fractional Short Circuit Method\&INC method can be implemented for tracing the maximum power for normal conditions but these methods fail under abnormal conditions.. The major limitation with above methods is they cannot distinguish local and global MPPT points. In addition to these a to\& fro motion is observed near MPP because of its fixed step size.

Hence the research work has laid foundation for novelty methods for overcoming the above limitations. Modified Methods such as Enhanced P\&O (EPO) [6],Modified Incremental conductance algorithm[7] and updated Open Circuit Voltage based method [8] are the few examples. In addition to these more advanced methods like ANN,AI and bio-inspired algorithms are predominate these days. Among them the particle swarm optimization (PSO) was the earliest method for implementing MPPT. Over the past many decades many methods MPPT techniques has evolved in the literature but many of the methods differ from the other in some aspects like complexity, speed of operation, tracking of irradiation, iteration methods to reach MPP, settling time, cost, efficiency, hardware and implementation of algorithm. A brief description of the familiar methods are shown below. 


\section{An Examination On Advanced MPPT Methods For PV Systems Under Normal \& Partial Shading Conditions}

\subsection{Perturb \& Observe Method}

The $\mathrm{P} \& \mathrm{O}$ is oneamong the distinguished MPPT algorithms due to its simplicity, simple ability and specifically it doesn't needany info relating to the PV array. The fundamental algorithm uses a set voltage step to extend or decrease the PV array power with its previous price. If the ability $\mathrm{PV}$ will increase that's $\Delta \mathrm{P}>0$ the rule continues to perturb the system within the same direction or instead in other way. This method is perennial at regular intervals of your time still the utmost power is reached i.e $\Delta \mathrm{P}=0$ [9]. The following figure-1 shows the basic algorithm involved in P\&O method.

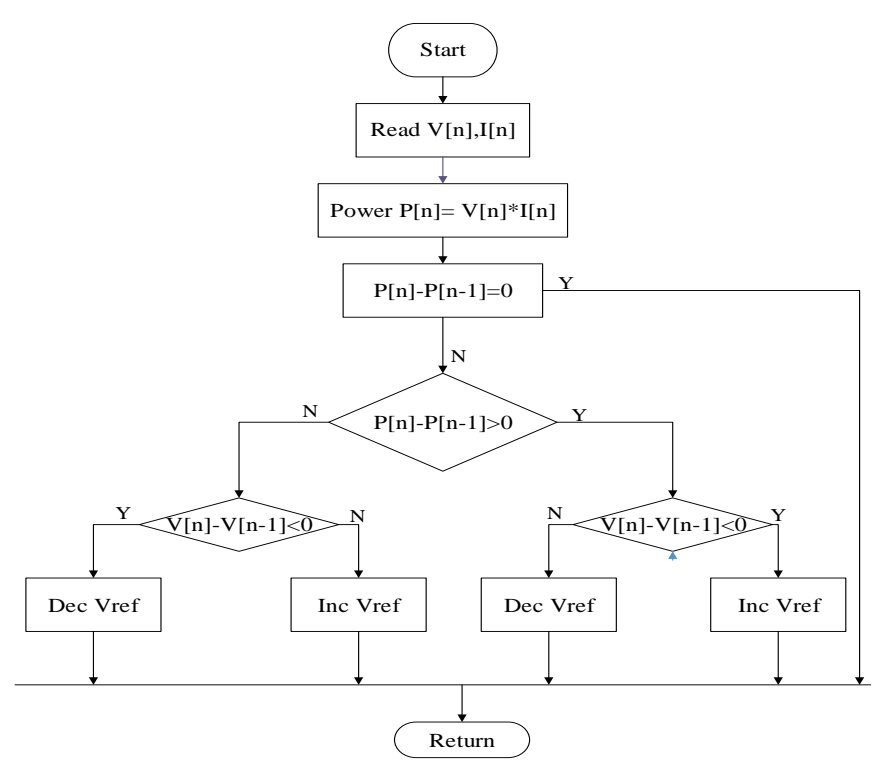

Figure 1: Algorithm for P\&O Method

If the length of voltage sample size is decreased then it takes more time to settle at MPP point where as if sample size is increased then MPP point is reached very quickly but oscillations are increased around MPP.

The main limitation with $\mathrm{P} \& \mathrm{O}$ methodology is that the operational point moves around maximum power point and takes long time to settle on that point. In addition to these when insolation changes rapidly this method would probably fail to track mppt[10].To overcome this limitation an error limit function can be used but still then this method could not work dynamically under variable atmospheric condition. To overcome this disadvantage method mostly used is Incremental conductance Method.

\subsection{Incremental Conductance Method}

The incremental conductance (INC) methodology as the name itself indicates, here the conductance of the method decides the ultimate power point that is the slope of the PV curve as shown in fig-2.Once the quantitative relation is positive its on the left aspect of MPP curve and negative indicates on the right aspect such that maximum outlet is achieved once the relation is zero.There are three equations which govern the working mechanism of incremental conductance method they are shown in the following figure.

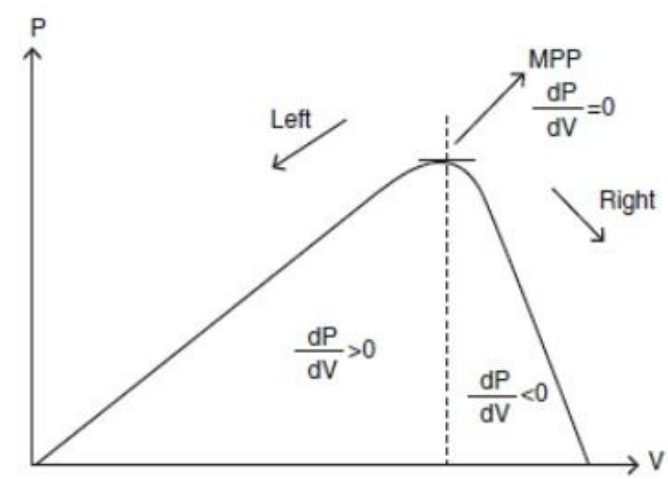

$\frac{d I}{d V}=-\frac{I}{V}$ At peak point

$\frac{d I}{d V}>-\frac{I}{V}$ left side of Peak point

$\frac{d I}{d V}<-\frac{I}{V}$

Figure 2: Basic Analogy of INC method based on PV curve and governing equations.

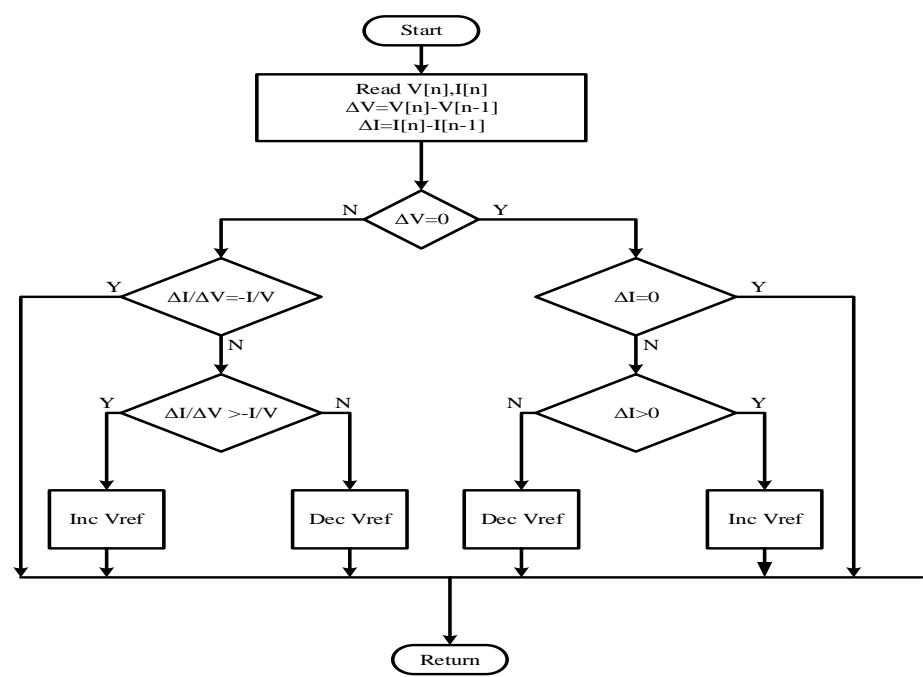

Figure 3: Flowchart for Incremental Conductance Method

There are two main advantages of INC method when compared with $\mathrm{P} \& \mathrm{O}$ method[11] that is it takes less iterations and make less oscillations before reaching the final point[12] and very rapidly corresponds to change in atmospheric conditions. The principal disadvantage of incremental conductance method is that the step size of oscillations are influenced by rate change of voltage that is the higher the oscillations the greater is the change in amplitude.

\subsection{Fractional open circuit voltage}

There is a relentless relation between the open circuit voltage $\left(\mathrm{V}_{\mathrm{oc}}\right)$ and $\mathrm{Max}$ voltage $\left(\mathrm{V}_{\mathrm{mp}}\right)$ underneath completely different irradiance and temperature which has finally given to relation as shown below

$V m p \cong k 1 V o c$ 
Where $k 1$ is a Proportional constant

Most notably the worthof $k l$ value varies between 0.71 to 0.78 which is dependent on the features of PV array being used. Once the value of $k l$ is $k_{n o w n} \mathrm{~V}_{\mathrm{mp}}$ can be calculated from the above equation.

The major advantage with Open circuit voltage is that it is very economical, easy to implement and doesn't require any complex control. However there is limitation with this method which results temporary losss of power to avoid this we are using a Reference cell from which Voc can be obtained. The values of reference cell should reflect the values of PV array.A feedback control is required to make the power converter to operate at maximum point but due to the approximation as shown in above equation it never operates at highest point. In addition to the above the presence of partial shading of PV array makes this method not realistic.

\subsection{Fractional Short circuit method}

The ratio of current scaling is more than the voltage scaling hence we can say that method is more accurate than earlier method. The ratio is generally given as follows

$$
\frac{I m}{I s c}=\frac{\text { Innew }}{\text { Iscnew }}=K=0.9
$$

Measurement of s/c current is massive downside throughout the operation of the system.
A bypass arrangement ought to be there wherever the contact current of the PV array ought to be measured. Since the current ratio is higher than voltage ratio most of the time fractional short circuit method is preferred over open circuit voltage method. The main limitation in voltage, current sampling the reference cell doesn't give the actual voltage of the big PV module in case of shaded conditions or unfair weather conditions hence it is not preferred method.

\subsection{Fuzzy logic control}

Application of fuzzy logic techniques to trace the MPP in PV systems has become additional accessible owing to the improved performance. The main advantage of fuzzy logic controller it doesn't require a exact mathematical model and can manage nonlinearity functions. In addition that the easy adaption of micro controllers have this method very popular among the available. Generally a fuzzy logic controller mainly consists of 3 stages as shown in following figure.

\section{Fuzzification Rulebook defuzzification}

Figure 4: Stages in fuzzy logic controller

During the first stage the numerical input variables are reborn into linguistic variables supported predefinedmembership functions. Here either five level or seven level fuzzy logic is adopted based on input variable. The higher the level indicates the higher the accuracy. The inputs generally given to MPPT logic controller are usually an error $(\mathrm{E})$ and change in error $(\Delta \mathrm{E})$. The error $(E)$ and the change in error $(\Delta E)$ are given as follows.

$$
\begin{aligned}
\mathrm{E}(\mathrm{n})= & \frac{P(n)-P(n-1)}{V(n)-V(n-1)} \\
& \Delta \mathrm{E}(\mathrm{n})=E(n)-E(n-1)
\end{aligned}
$$

\begin{tabular}{|c|c|c|c|c|c|}
\hline \multirow[b]{2}{*}{ E } & \multicolumn{5}{|l|}{$\Delta \mathrm{E}$} \\
\hline & NB & NS & $\mathrm{ZE}$ & PS & PB \\
\hline NB & ZE & $\mathrm{ZE}$ & NB & NB & NB \\
\hline NS & ZE & $\mathrm{ZE}$ & NS & NS & NS \\
\hline $\mathrm{ZE}$ & NS & ZE & $\mathrm{ZE}$ & ZE & PS \\
\hline PS & PS & PS & PS & ZE & ZE \\
\hline PB & PB & PB & PB & $\mathrm{ZE}$ & ZE \\
\hline
\end{tabular}

Table 1: Fuzzy logic rule book table

Once error and change in error are calculated, it can be transformed to linguistic variable wherethe fuzzy logic controller output, which is typically a change in duty ratio of power converter as shown in the above rule book table-1.Defuzzification represents the controller output wherever the linguistic variables are reborn into numeric variables providing analog signals for dominant the duty cycle of the ability device and thus to get the MPP. Under varying atmospheric conditions, the fuzzy logic control provides a better response.

\subsection{Neural Network}

The other technique of implementing MPPT method along with fuzzy logic controller is neural network. Generally any Neural network consists of 3 different layers as shown in the figure. The different nodes in each layer is totally based on the user requirement. The input parameters to the inner layer can be a combination of any one of the following PV array parameter like Voc, Isc,Irrad(G) \& temp(T) . The output layer may consists of several reference signals like duty cycle that are used to drive the power converter to operate near MPP. The optimal point near MPP is totally dependent on the methodology applied in the Hidden layer.The link established between the nodes is tagged \& determined through a well coaching method wherever the PV array are going to be tested over months and totally different patterns ar recorded. Since PV array is totally dependent on different input parameters hence a neural network should be designed for PV system which will guarantee accurate MPPT.

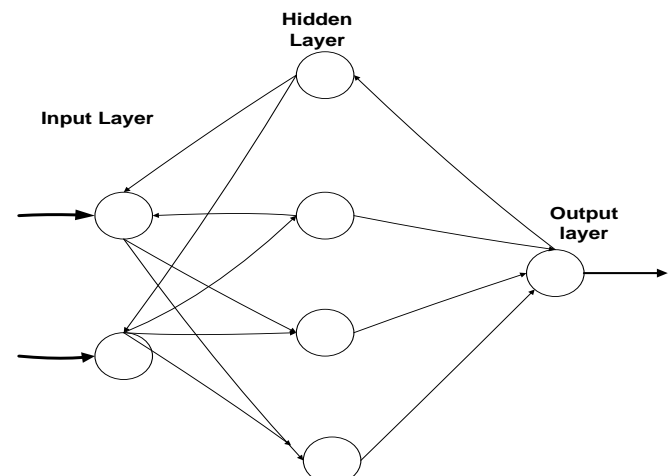

Figure 4: Neural Network Diagram 


\subsection{Ripple Correlation Method}

The Ripple Correlation Method (RCM) obtains the Maximum Power Point either by using voltage or current ripple generated in the PV cell because of shift action of power converters used.The time by-productof PV array with relation to time by-product of corresponding voltage or current is formed such power gradient is formed zero till the most purpose is obtained.If voltage, current \& power are greater than zero then we can say that the reference point is less than MPP on the other way we can understand it as above MPP. From the above anoloagy we can conclude that if power derivative \& voltage derivative are positive then the reference point is present on the left-hand side of PV curve otherwise it will be on right hand side and if gradient is zero it is at maximum point.

The main advantage with these method is its adoptability to rapid environmental change conditions \& doesn't require any information regarding PV array.

\section{Summary of MPPT Methods}

Table 2: Summary of MPPT methods

\begin{tabular}{|c|c|c|c|c|c|}
\hline MPPT Methods & $\begin{array}{c}\text { PV array data } \\
\text { Required ? }\end{array}$ & $\begin{array}{c}\text { Convergence } \\
\text { Speed }\end{array}$ & $\begin{array}{c}\text { Control } \\
\text { Strategy }\end{array}$ & $\begin{array}{c}\text { Output } \\
\text { variables }\end{array}$ & $\begin{array}{c}\text { MPPT } \\
\text { obtained }\end{array}$ \\
\hline P \& O & No & Varies & Low & V,I & Yes \\
\hline INC. & No & Varies & Medium & V.I & Yes \\
\hline Fuzzy logic & Yes & Fast & High & Varies & Yes \\
\hline Neural Network & Yes & Fast & High & Varies & Yes \\
\hline Open Circuit & Yes & Medium & Low & V & No \\
\hline Short Circuit & Yes & Medium & Low & I & No \\
\hline Ripple Correlation & NO & Fast & Low & Varies & Yes \\
\hline
\end{tabular}

\section{ADVANCEMENT IN MPPT TECHNIQUES}

The main limitation present in the $\mathrm{P} \& \mathrm{O}$ method that is the perturbation size and oscillations around the MPP value are reduced \& implemented in [13].The simulation and experimental results validate the method proposed in [13].Elgendy et all[14] presented detailed analysis \& evaluation of PV system using Perturb algorithm where simulation results matched with the experimental showing how fast a transient response of system is achieved under variable atmospheric conditions. An extensive analysis of different MPPT techniques[15] was done to pick up the best one where the results revealed that the fuzzy logic controller was best among them in steady state performance.

Kuo-Nan et all[16] proposed a viable technique where the Variable Fractional Order INC algorithm [17] when combined with the ExtenicsVariable Step Size [18] exhibited a good response in both steady and transient state. A hybrid MPPT technique [19] was proposed with a blend of genetic algorithm \& fuzzy logic controller where the obtained technique has given a good results when compared with existing fuzzy logic control. Dounis et all[20] has proposed an adaptive fuzzy logic controller for tracking MPP in PV system based on PID controller which is independent of atmospheric conditions \& achieved stability in both states.

A neural network based on genetic algorithm which uses a PI controller is presented [21].A very rare combination of neural network and fuzzy logic was made in [22] where a different combination of shading in PV panels are trained by neural networks and the corresponding signals are sent to the converter to locate MPP.

An adaptive control[23] involves the Ripple correlation method and Model Ref. adaptive control[24]where the first one is used for slow variations and the second one is used for fast variations. The proposed method reduces the wide variations in atmospheric conditions.

\section{BIO-INSPIRED MPPT TECHNIQUES FOR PARTIAL SHADING CONDITIONS}

\subsection{Particle Swarm Optimization (PSO)}

Particle Swarm optimization is based on the natural behaviour of group of birds, here each individual unit is known as Particle \& group is known as Swarm. Now each individual unit or particle tries to catch the local MPP based on their fitness function where as Swarm moves to global MPP. Both these process happens cumulatively [25].

In each iteration method a comparison is made between present operating point and difference in local maximum power point. After each sample the velocity of individual unit and positions are updated. One major limitation with the PSO method is initialization of particle position and time delay which are overcome in [26].Another setback in PSO that is complexity in calculation is reduced in accelerated Particle Swarm Optimization[27] by using a variable fitness parameter which resulted in usage of cheap microcontrollers. This [27] works in such way that only three points are selected for reference such that only two points are selected for $10 \%$ of Voc \& third one for $90 \%$ of Voc so that it doesn't fall under shade conditions. PSO methodology may also be utilized in standard strategies like $\mathrm{P} \& \mathrm{O}$ to eliminate the downside in methodology[28].

\subsection{Artificial Bee Colony Algorithm}

Artificial Bee colony algorithm (ABC) completely works on how a honeybee searches for the food [29]. Generally, the honeybees can be categorised into 3 types they are employee bee, Scout bee \& onlooker bee. The role of employee bees is to search for food location\&try to

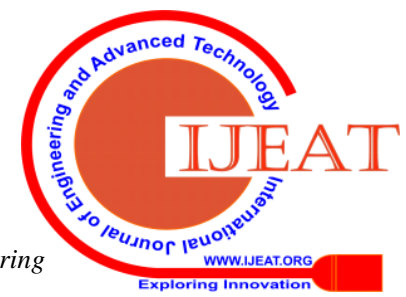


derive maximum food from it, whereas the Scout bees reveals the amount of food available $\&$ position. Based on the input given by Scout bees the onlooker bee guess the next optimal location to start the search process [30]. The same principle can be implemented for maximum power tracking algorithm.

The Artificial Bee colony algorithm starts with reference of population of bee, objective function, number of cycles, run time \& function variables [31,32]. The number of iterations are totally dependent on maximum number of cycles. The information relating to the placement of food is $1^{\text {st }}$ informed by employee bee. In the second step a duty cycle is calculated using fitness function. Depending on the given data the onlooker bees start looking for new duty cycle for best operating point. The computational time has been reduced in updated version of $\mathrm{ABC}$ [32].

\subsection{Cuckoo Search Algorithm (CS)}

This rule relies on cuckoo bird parasitic nature that stress on copy part of its life. Every cuckoo bird lays one egg at a time in an exceedingly at random chosen nest. The nest with top quality of eggs can move forward for next generation. If the eggssquare measure known host bird might destroy the eggs or leaves the nest.This gives to spot the new nest with nice likelihood. Applying the same concept to MPPT algorithm[33,34] here the references are given based on fixed voltage values. These references are fed to the power converter $\&$ initial power values are determined. The maximum power obtained from these is considered as local Maxima\& then global maxima are detected based on levy flight concept. The next set of voltages and power values are updated using levy flight distribution. The main limitation here is the random values are destroyed and new values are generated which is time consuming. So modifications are made to this algorithm.

\subsection{Firefly Algorithm}

This algorithm is completely based on the movement of fire flies[35-38]. The main basis for the algorithm is all the flies gets attracted to one another irrespective of their gender. Most of the time each flies get attracted to the brighter fly, here the brightness is dependent on fitness of the objective function.

Initially all the flies are distributed in predetermined area then the flies gets attracted towards the brightest one depending upon the environmental conditions. As they try to move towards the brightest spot they track the maximum power in real scenario. Oncethe condition is satisfied they get refrenced with random position. The fireflies are allottedwith different duty cycles in the range of $2 \%$ to $98 \%$ randomly. The converter operates corresponds to the movement of each fly and maximum power obtained is determined. This process is continued until the condition is satisfied. The tracking speed \& efficiency is improved by considering a modified firefly algorithm [39] .

\subsection{Flower Pollination Algorithm}

Flower pollination algorithmic program is predicated on the movement of fertilization in nature. The algorithm implementation [40-43] is similar to kind of MPPT approach. Here the fertilization betweencompletely different species represent cross-pollination

or world fertilization(global pollination) which occurs very long distance. The pollination between the same species is known as self-pollination or local-pollination similar to local MPP. The probability of reproduction depends upon the constancy of two flowers, which is based on the Levy flight that identifies the location of global pollination or local pollination.

The initialization to the algorithm is done based on population of pollen, iteration number, duty cycle \& probability of switching function. The fitness function decides the duty cycle with respect to maximum power and this value is compared to determine local MPP or global MPP. Initially the global MPP is identified based on whole population moves towards the point determining local MPP. In these way both local MPP and global MPP are evaluated in same sample by different pollination.

\section{REFERENCES}

1. S. E. D. A. Malaysia. (2013). Feed-in Tariff (FiT).

2. Gil-Antonio, L., Belem Saldivar-Marquez, M., \& Portillo-Rodriguez, O. (2016). Maximum power point tracking techniques in photovoltaic systems: A brief review. International Power Electronics Congress CIEP, 2016-August, 317-322.

3. J. B. Heng, J. Fu, B. Kong, Y. Chae, W. Wang, Z. Xie, A. Reddy, K. Lam, C. Beitel, C. Liao, C. Erben, Z. Huang, and Z. Xu, "x003e;23 x0025; high-efficiency tunnel oxide junction bifacial solar cell with electroplated cu gridlines," IEEE Journal of Photovoltaics, vol. 5, pp. 82-86, Jan 2015.

4. M. Taguchi, A. Yano, S. Tohoda, K. Matsuyama, Y. Nakamura, T Nishi- waki, K. Fujita, and E. Maruyama, "24.7 x0025; record efficiency hit solar cell on thin silicon wafer," IEEE Journal of Photovoltaics, vol. 4 pp. 96-99, Jan 2014

5. E. Moon, D. Blaauw, and J. D. Phillips, "Infrared energy harvesting in millimeter-scale gaas photovoltaics," IEEE Transactions on Electron Devices, vol. 64, pp. 4554-4560, Nov 2017

6. K. R. Bharath and P. Kanakasabapathy, "Implementation of enhanced perturb and observemaximum power point tracking algorithm to overcome partial shading losses," in 2016 International Conference on Energy Efficient Technologies for Sustainability ICEETS), pp. 62-67, April 2016.

7. D. Lakshmi and M. R. Rashmi, "A modified incremental conductance algorithm for partially shaded PV array,” Proc. 2017 IEEE Int. Conf. Technol. Adv. Power Energy Explor. Energy Solut. anIntell. Power Grid, TAP Energy 2017, vol. 2, no. c, pp. 1-6, 2018.

8. K. R. Bharath and E. Suresh, "Design and implementation of improved fractional open circuit voltage based maximum power point tracking algorithm for photovoltaic applications," International Journal of Renewable Energy Research, vol. 7, no. 3, 2017.

9. S. Z. M. Noor et al., "A Review of Single-Phase Single Stage Inverter Topologies for Photovoltaic System,” 2013 IEEE 4th Control Syst. Grad. Res. Colloq., pp. 69-74, 2013.

10. F. El Aamri, H. Maker, D. Sera, S. V. Spataru, J. M. Guerrero, and A Mouhsen, "A direct maximum power point tracking method for single-phase grid-connected PV inverters," IEEE Trans. Power Electron., vol. 33, no. 10, pp. 8961-8971, 2018.

11. D. Menniti, A. Burgio, N. Sorrentino, A. Pinnarelli, and G. Brusco, "An incremental conductance method with variable step size for MPPT: Design and implementation,” 2009 10th Int. Conf. Electr. Power Qual. Util. EPQU'09, pp. 2-6, 2009.

12. M. J. Hossain, B. Tiwari, and I. Bhattacharya, "An adaptive step size incremental conductance method for faster maximum power point tracking," 2017 IEEE 44th Photovolt. Spec. Conf. PVSC 2017, pp. 1-4, 2018.

13. K. Kollimalla, and M. K. Mishra, "Variable Perturbation Size AdaptiveP\&O MPPT Algorithm for Sudden Changes in Irradiance," IEEETRANSACTIONS ON SUSTAINABLE ENERGY, vol. 5, no. 3 , pp. 718-728, Jul. 2014.

14. Nurzaman, Tri Susilowati, and Arif Dian Wahyudi. "Drug Inventory Information System In Asy-Syifaa Yukum Jaya Islamic Hospital." International Journal of Communication and Computer Technologies 7.2 (2019), 27-31. Print. doi: $10.31838 / \mathrm{ijccts} / 07.02 .07$ 
15. Sreedhar Ranjan Das, Bibhuti Bhusanpanigrahi, Manojkumar.Pani. "A Review on compatibility of "Sucralfate" in bi layer floating tablet for treatment of ulcer in pregnancy.." International Journal of Pharmacy $\begin{array}{llllll}\text { Research \& } \quad \text { Technology } 10.1 & \text { (2020), 12-16. Print. }\end{array}$ doi:10.31838/ijprt/10.01.04

16. Y. Kuo-Nan, L. Chih-Kang, and Y. Her-Terng, "A New Fractional-OrderBased Intelligent Maximum Power Point Tracking Control Algorithm forPhotovoltaic Power Systems," International Journal of Photoenergy, vol.2015, pp. 1-8, 2015.

17. J. Li and H. Wang, "A novel stand-alone PV generation system based on variable step size INC MPPT and SVPWM control," Proceedings of theIEEE 6th International Power Electronics and Motion Control Conference (IPEMC 09), pp. 21552160, May 2009.

18. S. Hong-Chun, H. Ze-Jiang, S. Shi-Yun, and Y. Qing, "The faultdiagnosis algorithm for transformer based on Extenics and rough settheory," in Proceedings of the 3rd International Conference on Electric Utility Deregulation and Restructuring and Power Technologies (DRPT 08), pp. 12691272, Nanjing, China, Apr. 2008.

19. A. Rezaei and S. A. Gholamian, "Optimization of New Fuzzy Logic Controller by Genetic Algorithm for Maximum Power Point Tracking in Photovoltaic System," ISESCO Journal of Science and Technology, vol.9, pp. 9-16, May 2013.

20. A. I. Dounis, P. Kofinas, C. Alafodimos, and D. Tseles, “Adaptive fuzzy gain scheduling PID controller for maximum power point tracking of photovoltaic system," Renewable Energy, vol. 60, pp. 202-214, Jun. 2013. 